\title{
Effectiveness of Nicardipine for Blood Pressure Control in Patients with Subarachnoid Hemorrhage
}

\author{
Sang Yong Kim, MD, Seong Min Kim, MD, PhD, Moon Sun Park, MD, PhD, Han Kyu Kim, MD, PhD, Ki Seok \\ Park, MD, Seong Young Chung, MD, PhD \\ Department of Neurosurgery, Eulji University Hospital, Daejeon, Korea
}

\begin{abstract}
Objective: The purpose of the study is to determine the effectiveness and safety of nicardipine infusion for controlling blood pressure in patients with subarachnoid hemorrhage (SAH).

Methods: We prospectively evaluated 52 patients with SAH and treated with nicardipine infusion for blood pressure control in a 29 months period. The mean blood pressure of pre-injection, bolus injection and continuous injection period were compared. This study evaluated the effectiveness of nicardipine for each Fisher grade, for different dose of continuous nicardipine infusion, and for the subgroups of systolic blood pressure.

Results: The blood pressure measurement showed that the mean systolic blood pressure / diastolic blood pressure (SBP/DBP) in continuous injection period $(120.9 / 63.0 \mathrm{mmHg})$ was significantly lower than pre-injection period $(145.6 / 80.3 \mathrm{mmHg})$ and bolus injection period $(134.2 / 71.3 \mathrm{mmHg})$, and these were statistically significant $(\rho<0.001)$. In each subgroups of Fisher grade and different dose, SBP/DBP also decreased after the use of nicardipine. These were statistically significant $(\rho<0.05)$, but there was no significant difference in effectiveness between subgroups $(\rho>0.05)$. Furthermore, controlling blood pressure was more effective when injecting higher dose of nicardipine in higher SBP group rather than injecting lower dose in lower SBP group, and it also was statistically significant $(\rho<0.05)$. During the infusion, hypotension and cardiogenic problems were transiently combined in five cases. However, patients recovered without any complications.

Conclusion: Nicardipine is an effective and safe agent for controlling acutely elevated blood pressure after SAH. A more systemic study with larger patients population will provide significant results and will bring solid evidence on effectiveness of nicardipine in SAH.
\end{abstract}

J Cerebrovasc Endovasc Neurosurg. 2012 June; 14(2):84 89

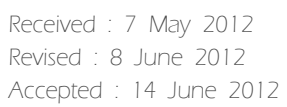

Correspondence to Seong Young Chung, MD Department of Neurosurgery, Eulji University Hospital, Seo-gu, Dunsan-2dong, 1306, Daejeon, 302-799 Korea

Tel : 10011 82-42-611-3442

FAX: $1001182-42-611-3444$

E-mail : neurocsy@eulji.ac.kr

\section{INTRODUCTION}

Non-traumatic subarachnoid hemorrhage (SAH) occupies approximately 5-6\% of all strokes. ${ }^{23)}$ The incidence of SAH is around six cases per 100,000 patient years, and the most common cause of SAH is a rup- ture of a saccular cerebral aneurysm. ${ }^{21)}$ Aneurysmal rebleeding is a serious and disastrous complication of $\mathrm{SAH}$, and it comes with high mortality and morbidity. The incidence of aneurysmal rebleeding is considerably high within hours after the initial SAH $(21.5 \%$ within 72 hours). ${ }^{8)}$ Unfortunately, re-bleeding cannot 
be absolutely controlled even in authoritative neurosurgical centers that performs early aneurysm repair, such as aneurysm neck clipping or endovascular coiling. Several investigators have reported that rebleeding occurs more often in patients with advanced age, larger aneurysms, poor clinical condition, and increased systolic arterial blood pressure (SBP) on admission. ${ }^{512)}$ The incidence of rebleeding was significantly higher in patients with extremely high SBP group (> $200 \mathrm{mmHg}$ ) (55.6\%) than in the lower SBP groups (<150 mmHg, 150-200 mmHg). ${ }^{7}$ Therefore, it is important to control the blood pressure.

Nicardipine(Perdipine ${ }^{\circledR}$ ) is a dihydropyridine type calcium channel blocker and has strong antihypertensive activity and a particular cerebrovascular profile. ${ }^{2)}$ Nicardipine has been used to control blood pressure in severe hypertension after ischemic stroke, traumatic brain injury, intracerebral hemorrhage (ICH), and to improve vasospasm after SAH. ${ }^{9-11) 1618)}$

In a recent study, Qureshi et al. ${ }^{19)}$ reported the feasibility and safety of nicardipine use in treatment of acute hypertension with $\mathrm{ICH}$, and Varelas et al. ${ }^{22}$ demonstrated nicardipine infusion for controlling elevated blood pressure after SAH. However, the study showing controlling acute hypertension after $\mathrm{SAH}$ is limited. The purpose of this study is to evaluate the effectiveness and safety of nicardipine infusion for controlling blood pressure in patients with $\mathrm{SAH}$, and compare the effectiveness for each Fisher grade, for different dose of continuous nicardipine infusion, and for various ranges of systolic blood pressure.

\section{MATERIALS AND METHODS}

We prospectively evaluated 112 patients with ruptured aneurysmal SAH admitted to the intensive care unit and treated them with nicardipine for 29 months period (January 2009 - May 2011). The diagnosis of ruptured aneurysmal SAH was made by history, clinical features, either computed tomographic angiography of the brain or four-vessels cerebral angiog- raphy to evaluate the presence of an intracranial aneurysm. The content and method was confirmed by association of clinical trial and informed consent was received from patients and/or their family members. Patients with active intracranial bleeding, coagulopathy, pregnancy, myocardial infarction, chronic heart failure, and chronic kidney disease were eliminated from the study along with patients who were infused with other types of calcium channel blocker within two-hour period.

Fifty two patients enrolled, and their age ranged from 22 to 89 with the mean of 56.9. Twenty two patients were male and 30 were female. Nicardipine was diluted with normal saline or $5 \%$ dextrose water for intravenous injection, and it was infused until the target blood pressure was reached and settled. The goal of the treatment was to reduce and maintain the SBP less than $140 \mathrm{mmHg}$ and diastolic blood pressure (DBP) less than $100 \mathrm{mmHg}$ (mean arterial pressure less than about $110 \mathrm{mmHg}$ ) within 24 hours from the treatment started. Patients were divided into three groups according to the injection period. Pre-injection period refers to the condition before nicardipine injection. Bolus injection period is controlling blood pressure. Continuous injection period is when blood pressure control failed even after the bolus injection of nicardipine. The continuous intravenous nicardipine injection was initiated with a rate of $5 \mathrm{mg} / \mathrm{hr}$. If the mean arterial pressure was not reduced to 110 $\mathrm{mmHg}$ after 15 minutes, the infusion dose was increased by $2.5 \mathrm{mg} / \mathrm{hr}$. The $2.5 \mathrm{mg} / \mathrm{hr}$ increments continued every 15 minutes until the maximum dose of $15 \mathrm{mg} / \mathrm{hr}$ was reached. Blood pressure was monitored using an intra-arterial catheter. We also evaluated the influence of infusion dosage of nicardipine according to SBP/DBP. $1 \mathrm{mg}$ of nicardipine was used in patients with SBP between 140 and $160 \mathrm{mmHg}$, and $2 \mathrm{mg}$ in patients with SBP between 161 and $180 \mathrm{mmHg}$.

Data were recorded for all patients using a standard data collection form. The data were analyzed by SPSS (version 12.0). Statical analysis was performed with 
paired T-test and chi-squared test. Statistical significance was established at $p<0.05$.

\section{RESULTS}

Fifty two patients, who fulfilled the condition, were injected with nicardipine. Their demographics and clinical characteristics are presented in table (Table 1).

In forty patients who were not responsive to bolus injection, the mean blood pressure in three periods were compared. From pre-injection period (145.6/80.3 $\mathrm{mmHg}), 11.4 / 9.0 \mathrm{mmHg}$ was reduced after bolus injection, whereas $24.7 / 17.3 \mathrm{mmHg}$ was reduced after continuous injection. The effect of nicardipine in controlling blood pressure was statistically significant $(p$ $<0.001$ ) (Table 2).

Effectiveness of nicardipine was analysed according to three conditions : Fisher grade, continuous infusion dose of nicardipine, and ranges of systemic blood pressure. At first, all the subgroups of Fisher grade showed decrease in SBP/DBP using nicardipine. The mean SBP/DBP decreased by 38.0/22.5 mmHg ( $p=$ $0.037 / p=0.038)$ in Fisher grade $\mathrm{I}(\mathrm{n}=4), 15.9 / 7.7 \mathrm{mmHg}$ $(p=0.001 / p=0.035)$ in grade II $(\mathrm{n}=10), 22.2 / 15.6 \mathrm{mmHg}$ $(p<0.001 / p=0.004)$ in grade III $(\mathrm{n}=16)$, and $28.6 / 17.2$ $\mathrm{mmHg}(p<0.001 / p=0.001)$ in grade IV $(\mathrm{n}=18)$, and all of them were statistically significant. However, there was no difference in effectiveness between subgroups. (SBP between subgroups $p=0.144$, DBP between subgroups $p=0.299$ ) (Table 3 ). Secondly, each subgroups with different dosage of nicardipine lowered SBP/ DBP. In low dose group $(\mathrm{n}=20)(\leq 5 \mathrm{mg} / \mathrm{hr})$, the mean SBP/DBP decreased by 11.8/7.9 $\mathrm{mmHg}(p<0.001 / p=$ $0.002)$. It decreased by $13.1 / 9.7 \mathrm{mmHg}(p<0.001 / p=$ $0.046)$ in medium dose group $(n=12)(6-10 \mathrm{mg} / \mathrm{hr})$, and 15.0/9.2 $\mathrm{mmHg}(p=0.003 / p=0.007)$ in high dose group $(\mathrm{n}=10)(11-15 \mathrm{mg} / \mathrm{hr})$. There was no difference in effectiveness between subgroups. (SBP between subgroups $p=0.575$, DBP between subgroups $p=0.404$ ) (Table 4). Finally, $1 \mathrm{mg}$ of nicardipine was used in patients with SBP between 140 and $160 \mathrm{mmHg}(\mathrm{n}=18)$, and $2 \mathrm{mg}$ in patients with SBP between 161 and 180
Table 1. Demographics and clinical characteristics of the patients with subarachnoid hemorrhage treated with intravenous nicardipine.

\begin{tabular}{|c|c|}
\hline Variable & Patients $(\%)$ \\
\hline Male : Female & $22: 30$ \\
\hline Age (mean \pm SD) & $56.9 \pm 13.2$ \\
\hline History of Hypertension & $18(34.6 \%)$ \\
\hline History of Diabetes Mellitus & $2(3.8 \%)$ \\
\hline \multicolumn{2}{|l|}{ Hunt and Hess grade } \\
\hline 1 & $0(0 \%)$ \\
\hline$\|$ & $18(34.6 \%)$ \\
\hline III & $28(53.8 \%)$ \\
\hline IV & $5(9.6 \%)$ \\
\hline V & $1(1.9 \%)$ \\
\hline \multicolumn{2}{|l|}{ Fisher grade } \\
\hline । & $4(7.7 \%)$ \\
\hline$\|$ & $12(23.1 \%)$ \\
\hline III & $17(32.7 \%)$ \\
\hline IV & $19(36.5 \%)$ \\
\hline Intraventricular hemorrhage & $12(23.1 \%)$ \\
\hline Hydrocephalus & $2(3.8 \%)$ \\
\hline Seizure & $2(3.8 \%)$ \\
\hline \multicolumn{2}{|l|}{ Location of aneurysm or lesion } \\
\hline Internal carotid artery & $5(9.6 \%)$ \\
\hline Middle cerebral artery & $8(15.4 \%)$ \\
\hline Anterior cerebral artery & $2(3.8 \%)$ \\
\hline Anterior communicating artery & $18(34.6 \%)$ \\
\hline Posterior communicating artery & $11(21.2 \%)$ \\
\hline Basilar artery, Superior cerebellar artery & $5(9.6 \%)$ \\
\hline Vertebral artery & $1(1.9 \%)$ \\
\hline Anterior/Posterior inferior cerebellar artery & $2(3.8 \%)$ \\
\hline \multicolumn{2}{|l|}{ Treatment of aneurysm } \\
\hline Clipping & $30(57.7 \%)$ \\
\hline Coiling & $22(42.3 \%)$ \\
\hline \multicolumn{2}{|l|}{ Complications during nicardipine infusion } \\
\hline Rebleeding & $0(0 \%)$ \\
\hline Hypotension & $1(1.9 \%)$ \\
\hline Cardiogenic (Arrhythmia, Tachycardia) & $4(7.7 \%)$ \\
\hline Renal dysfunction & $0(0 \%)$ \\
\hline
\end{tabular}

mmHg. In patients with SBP below $160 \mathrm{mmHg}(\mathrm{n}=9)$, the mean SBP/DBP decreased by $19.8 / 14.2 \mathrm{mmHg}(p$ $<0.001 / p<0.001$ ), and it dropped by $48.0 / 30.8 \mathrm{mmHg}$ $(p<0.001 / p=0.008)$ in patients with SBP above 160 $\mathrm{mmHg}$. There was significant decrease in blood pressure in both groups (SBP in both groups $p<0.001$, DBP in both groups $p=0.01$ ) (Table 5). 
Table 2. Average SBP, DBP in pre-injection period, bolus injection period and continuous injection period.

\begin{tabular}{|c|c|c|c|c|c|c|c|}
\hline & Pre SBP & Post SBP & $p$-value & Pre DBP & Post DBP & $p$-value & Patient \\
\hline Pre-injection & $145.6 \pm 13.5$ & & & $\begin{array}{c}80.3 \\
\pm 15.7\end{array}$ & & & \multirow{3}{*}{40} \\
\hline Bolus injection & & $134.2 \pm 10.4$ & $<0.001$ & & $71.3 \pm 10.5$ & $<0.001$ & \\
\hline Continuous injection & & $120.9 \pm 7.3$ & $<0.001$ & & $63.0 \pm 9.1$ & $<0.001$ & \\
\hline
\end{tabular}

SBP = systolic blood pressure; DBP = diastolic blood pressure

Table 3. Average of pre and post SBP and DBP for each Fisher grade. (SBP between subgroups $p=0.144$, DBP between subgroups $p=0.299$ )

\begin{tabular}{cccccccc}
\hline Fisher Grade & Pre SBP & Post SBP & $\rho$-value & Pre DBP & Post DBP & $\rho$-value & Patient \\
\hline I & $149.8 \pm 16.3$ & $111.8 \pm 25.4$ & 0.037 & $82.8 \pm 17.5$ & $60.5 \pm 10.7$ & 0.038 & 4 \\
II & $141.5 \pm 9.1$ & $125.6 \pm 14.9$ & 0.001 & $74.7 \pm 12.0$ & $67.0 \pm 10.7$ & 0.035 & 10 \\
II & $144.8 \pm 14.3$ & $122.6 \pm 9.1$ & $<0.001$ & $85.8 \pm 20.4$ & $70.2 \pm 10.0$ & 0.004 & 16 \\
IV & $150.7 \pm 14.7$ & $122.1 \pm 12.1$ & $<0.001$ & $84.3 \pm 17.4$ & $67.1 \pm 11.7$ & 0.001 & 18 \\
\hline
\end{tabular}

Table 4. Average of pre and post SBP and DBP in different dosage of nicardipine. (SBP between subgroups $p=0.575$, DBP between subgroups $p=0.404$ )

\begin{tabular}{lccccccc}
\hline Continuous infusion dose & Pre SBP & Post SBP & $p$-value & Pre DBP & Post DBP & $p$-value & Patient \\
\hline Low dose $(\leq 5 \mathrm{mg} / \mathrm{hr})$ & $130.3 \pm 10.1$ & $118.5 \pm 7.2$ & $<0.001$ & $69.3 \pm 10.4$ & $61.4 \pm 11.2$ & 0.002 & 20 \\
Medium dose $(6-10 \mathrm{mg} / \mathrm{hr})$ & $134.3 \pm 7.3$ & $121.2 \pm 8.1$ & $<0.001$ & $71.2 \pm 12.8$ & $61.5 \pm 9.7$ & 0.046 & 12 \\
High dose $(11-15 \mathrm{mg} / \mathrm{hr})$ & $138.5 \pm 14.5$ & $123.5 \pm 6.8$ & 0.003 & $73.0 \pm 7.8$ & $63.8 \pm 7.7$ & 0.007 & 10 \\
\hline
\end{tabular}

Table 5. Average of pre and post SBP and DBP, in patients with SBP 140-160 mmHg and 161-180 mmHg. Patients with SBP lower than $140 \mathrm{mmHg}$ were excluded. (SBP in both groups $p<0.001$, DBP in both groups $p=0.01$ )

\begin{tabular}{lccccccc}
\hline SBP $(\mathrm{mmHg})$ & Pre SBP & Post SBP & $\rho$-value & Pre DBP & Post DBP & $\rho$-value & Patient \\
\hline $140-160$ & $149.8 \pm 5.3$ & $130.0 \pm 8.2$ & $<0.001$ & $85.3 \pm 8.5$ & $71.1 \pm 10.8$ & $<0.001$ & 18 \\
$161-180$ & $168.4 \pm 8.1$ & $120.0 \pm 12.8$ & $<0.001$ & $99.4 \pm 26.3$ & $68.6 \pm 12.0$ & 0.008 & 9 \\
\hline
\end{tabular}

There were few complication during nicardipine infusion (Table 1). No patient developed rebleeding and renal dysfunction during the period. In one case, which infused $2.5 \mathrm{mg} / \mathrm{hr}$ of nicardipine, the SBP of the patient dropped to $94 \mathrm{mmHg}$ and DBP to 33 $\mathrm{mmHg}$; thus, nicardipine had to be pre-terminated. Cardiogenic problems occurred in four patients. Tachycardia with heart rates more than 120 beats per minute appeared in two patients, and arrhythmia was combined in two patients, in which one of them showed ventricular premature contraction, and another showed atrial fibrillation.

\section{DISCUSSION}

Nicardipine, a dihydropyridine calcium channel antagonist, is a vasoselective agent with minimal cardiac inotropic effects. ${ }^{23}$ ) This is the ideal agent for shortterm management of hypertension because of short half life and relatively rapid onset/offset of action in lowering blood pressure with minimal adverse events. ${ }^{6}$ Hypotension, arrhythmia and tachycardia were some adverse effects observed in this study but there was no severe events.

There has been studies comparing the effectiveness 
of nicardipine and sodium nitroprusside or nicardipine and labetalol and evaluating effectiveness of nicardipine in traumatic brain injury, $\mathrm{SAH}, \mathrm{ICH}$, arteriovenous malformation, and hypoxic brain injury. ${ }^{13) 16) 20)}$ Recently, Varelas et al. $^{22)}$ reported effectiveness and safety of nicardipine infusion in reducing SBP and DBP to pre-specified goal. Nicardipine achieved SBP control in $59.9 \%$ of hourly infusion measurements.

Intravenous nicardipine has already been included in the published guidelines for blood pressure control in ischemic stroke, $\mathrm{ICH}^{\left.1)^{4}\right)}$ The recently published guidelines for SAH also include nicardipine, however, without available data for such a use.")

In this study, continuous injection was the most effective method in decreasing blood pressure compared with bolus injection. In some cases, which we manipulated the injection method from bolus to continuous, the influence of bolus injection cannot be ignored even though nicardipine is a short acting agent. This study also showed no significant difference in effectiveness of nicardipine to control blood pressure for each Fisher grade and for different continuous dosage of nicardipine. Nicardipine showed significant decrease in all the subgroups of each categories; however, there was no significant difference within subgroups of Fisher grade and dosage. On the contrary, the effectiveness of nicardipine was significantly different between a group of SBP with 140-160 $\mathrm{mmHg}$ and $161-180 \mathrm{mmHg}$.

Nicardipine is known as a safe medication. During the research period, there was neither rebleeding nor renal dysfunction. Transient complications, such as hypotension, arrhythmia, and tachycardia, appeared, but patients recovered without any permanent deficit.

The risk of rebleeding decrease as the blood pressure decreases, but lowering the blood pressure is not everything. One study reported a increase in rebleeding risk with blood pressure over $160 \mathrm{mmHg}$ compared with $140 \mathrm{mmHg}$, and rebleeding incidence decreased when anti-hypertensive treatment was used. ${ }^{17}$ In contrast, risk of cerebral infarction rate increases with low blood pressure. ${ }^{24)}$ The optimal blood pressure after SAH would dependent on multiple factors. In addition, appropriate management of blood pressure is necessary because most rebleeding occurs due to the change of blood pressure rather than absolute blood pressure level itself. ${ }^{15)}$ The most recent guideline for the management of $\mathrm{SAH}$ recommends that "blood pressure should be monitored and controlled to balance the risk of stroke, hypertension-related rebleeding, and maintenance of cerebral perfusion pressure" as Class I, Level of Evidence B. ${ }^{3)}$ Until systematic treatment algorithms are developed, the optimal blood pressure may vary considerably and be dependent on physician's preferences.

The limitation of this study is that there is no correlation between age, clinical or past medical history and the influence that these factors will have on patient's blood pressure. Also medical conditions such as seizure or hydrocephalus were not considered, and the number of study population was too small to represent the accurate outcome. The initial blood pressure of each patient and the reaction to injection were not reflected on setting and reaching a goal blood pressure.

\section{CONCLUSIONS}

Nicardipine is an effective medication in controlling acute hypertension or dropping blood pressure in $\mathrm{SAH}$. Because continuous infusion of nicardipine has better effects in blood pressure control, it is recommendable when blood pressure is not controlled with bolus infusion if there is no symptom of adverse effects. There was no significant difference in effectiveness of nicardipine within subgroups of Fisher grade and infusion dosage. It was found that higher dose of nicardipine injection with higher SBP is more effective in controlling blood pressure. Nicardipine also seems to be safe except for very few unsevere complications. A systemic study with larger number of patients will be necessary to plan a more precise 
guideline for the use of nicardipine in controlling blood pressure with SAH.

\section{REFERENCES}

1. Adams HP Jr, del Zoppo G, Alberts MJ, Bhatt DL, Brass L, Furlan A, et al. Guidelines for the early management of adults with ischemic stroke: a guideline from the American Heart Association/American Stroke Association Stroke Council, Clinical Cardiology Council, Cardiovascular Radiology and Intervention Council, and the Atherosclerotic Peripheral Vascular Disease and Quality of Care Outcomes in Research Interdisciplinary Working Groups: the American Academy of Neurology affirms the value of this guideline as an educational tool for neurologists. Stroke. 2007 May;38(5):1655-711.

2. Amenta F, Lanari A, Mignini F, Silvestrelli G, Traini E, Tomassoni D. Nicardipine use in cerebrovascular disease: a review of controlled clinical studies. J Neurol Sci. 2009 Aug 15;283(1-2):219-23.

3. Bederson JB, Connolly ES Jr, Batjer HH, Dacey RG, Dion JE, Diringer MN, et al. Guidelines for the management of aneurysmal subarachnoid hemorrhage: a statement for healthcare professionals from a special writing group of the Stroke Council, American Heart Association. Stroke. 2009 Mar;40(3):994-1025.

4. Broderick J, Connolly S, Feldmann E, Hanley D, Kase C, Krieger D, et al. Guidelines for the management of spontaneous intracerebral hemorrhage in adults: 2007 update: a guideline from the American Heart Association/ American Stroke Association Stroke Council, High Blood Pressure Research Council, and the Quality of Care and Outcomes in Research Interdisciplinary Working Group. Stroke. 2007 Jun;38(6):2001-23.

5. Cha KC, Kim JH, Kang HI, Moon BG, Lee SJ, Kim JS. Aneurysmal rebleeding: factors associated with clinical outcome in the rebleeding patients. J Korean Neurosurg Soc. 2010 Feb;47(2):119-23.

6. Curran MP, Robinson DM, Keating GM. Intravenous nicardipine: its use in the short-term treatment of hypertension and various other indications. Drugs. 2006;66(13): 1755-82.

7. Fujii Y, Takeuchi S, Sasaki O, Minakawa T, Koike T, Tanaka R. Ultra-early rebleeding in spontaneous subarachnoid hemorrhage. J Neurosurg. 1996 Jan;84(1):35-42.

8. Guo LM, Zhou HY, Xu JW, Wang Y, Qiu YM, Jiang JY. Risk factors related to aneurysmal rebleeding. World Neurosurg. 2011 Sep-Oct;76(3-4):292-8; discussion 253-4.

9. Haley EC Jr, Kassell NF, Torner JC. A randomized controlled trial of high-dose intravenous nicardipine in aneurysmal subarachnoid hemorrhage. A report of the Cooperative Aneurysm Study. J Neurosurg. 1993 Apr; 78(4):537-47.

10. Haley EC Jr, Kassell NF, Torner JC. A randomized trial of nicardipine in subarachnoid hemorrhage: angiographic and transcranial Doppler ultrasound results. A report of the Cooperative Aneurysm Study. J Neurosurg. 1993 Apr; 78(4):548-53.
11. Haley EC Jr, Kassell NF, Torner JC, Truskowski LL, Germanson TP. A randomized trial of two doses of nicardipine in aneurysmal subarachnoid hemorrhage. A report of the Cooperative Aneurysm Study. J Neurosurg. 1994 May;80(5):788-96.

12. Kassell NF, Torner JC. Aneurysmal rebleeding: a preliminary report from the Cooperative Aneurysm Study. Neurosurgery. 1983 Nov;13(5):479-81.

13. Liu-Deryke $X$, Janisse J, Coplin WM, Parker D Jr, Norris G, Rhoney DH. A comparison of nicardipine and labetalol for acute hypertension management following stroke. Neurocrit Care. 2008;9(2):167-76.

14. Martin CO, Rymer MM. Hemorrhagic stroke: aneurysmal subarachnoid hemorrhage. Mo Med. 2011 Mar-Apr;108(2):124-7.

15. Mayberg MR, Batjer HH, Dacey R, Diringer M, Haley $\mathrm{EC}$, Heros RC, et al. Guidelines for the management of aneurysmal subarachnoid hemorrhage. A statement for healthcare professionals from a special writing group of the Stroke Council, American Heart Association. Stroke. 1994 Nov;25(11):2315-28.

16. Narotam PK, Puri V, Roberts JM, Taylon C, Vora Y, Nathoo N. Management of hypertensive emergencies in acute brain disease: evaluation of the treatment effects of intravenous nicardipine on cerebral oxygenation. J Neurosurg. 2008 Dec;109(6):1065-74.

17. Ohkuma H, Tsurutani H, Suzuki S. Incidence and significance of early aneurysmal rebleeding before neurosurgical or neurological management. Stroke. 2001 May;.32(5):1176-80.

18. Powers WJ, Zazulia AR, Videen TO, Adams RE, Yundt $\mathrm{KD}$, Aiyagari V, et al. Autoregulation of cerebral blood flow surrounding acute ( 6 to 22 hours) intracerebral hemorrhage. Neurology. 2001 Jul 10;57(1):18-24.

19. Qureshi AI, Harris-Lane P, Kirmani JF, Ahmed S, Jacob M, Zada $Y$, et al. Treatment of acute hypertension in patients with intracerebral hemorrhage using American Heart Association guidelines. Crit Care Med. 2006 Jul;34 (7):1975-80.

20. Roitberg BZ, Hardman J, Urbaniak K, Merchant A, Mangubat EZ, Alaraj A, et al. Prospective randomized comparison of safety and efficacy of nicardipine and nitroprusside drip for control of hypertension in the neurosurgical intensive care unit. Neurosurgery. 2008 Jul;63 (1):115-20; discussion 120-1.

21. van Gijn J, Rinkel GJ. Subarachnoid haemorrhage: diagnosis, causes and management. Brain. $2001 \mathrm{Feb} ; 124(\mathrm{Pt} 2)$ : 249-78.

22. Varelas PN, Abdelhak T, Wellwood J, Shah I, Hacein-Bey L, Schultz L, Mitsias P. Nicardipine infusion for blood pressure control in patients with subarachnoid hemorrhage. Neurocrit Care. 2010 Oct;13(2):190-8.

23. Whiting RL, Dow RJ, Graham DJ, Mroszczak EJ. An overview of the pharmacology and pharmacokinetics of nicardipine. Angiology. 1990 Nov;41(11 Pt 2):987-91.

24. Wijdicks EF, Vermeulen M, Murray GD, Hijdra A, van Gijn J. The effects of treating hypertension following aneurysmal subarachnoid hemorrhage. Clin Neurol Neurosurg. 1990;92(2):111-7. 